ISSN: 0213-3563

https://doi.org/10.14201/azafea202123255275

\title{
UNA RELECTURA ANTIHUMANISTA DEL CONCEPTO DE SUJETO EN BADIOU Y ŽIŽEK
}

\author{
An Antibumanism Rereading of the Concept \\ of Subject in Badiou and Žižek
}

Eduardo Alberto LEÓN

Flacso-Ecuador

Enviado: 15 de abril de 2021

Aceptado: 18 de abril de 2020

\section{RESUMEN}

En este artículo se expondrá en primer lugar la crítica de Badiou sobre el sujeto humanista y su propio concepto de sujeto, un sujeto que está claramente inspirado en Lacan pero que va más allá de la subjetivación de la falta de este. Luego me dirigiré al colega de Badiou en el campo antihumanista, Slavoj Žižek, y su crítica lacaniana de Badiou. Se afirmará que es su interpretación diferente del Real lacaniano lo que explica la disputa subyacente entre ellos. Mientras que el sujeto de Žižek es infundado, por otro lado, la concepción de Badiou de forzar lo Real confiere al sujeto un grado de consistencia que facilita la articulación de proyectos políticos específicos.

Palabras clave: Sujeto; antihumanismo; impulso; falta; Real; acontecimiento; verdad.

\section{ABSTRACT}

In this research paper will be discuss Badiou's critique of the humanistic subject and his own concept of subject, a subject that is clearly inspired by Lacan but goes beyond the subjectivation of the lack. Then I will talk about Badiou's colleague in the anti-humanist camp, Slavoj Žižek, and his Lacanian criticism of Badiou. It will be will affirmed that is their different interpretation from the Lacanian Real that explains the underlying dispute between them. Although Žižek's subject is groundless, on the other hand, 
Badiou's conception of forcing the Real gives the subject a degree of consistency that facilitates the articulation of specific political projects.

Key words: Subject; antihumanism; impulse; lack; Real; event, truth.

\section{INTRODUCCIÓN}

Está claro que Badiou quiere mantener una concepción post-sartreana del sujeto, y que este ha sido el caso de sus primeros trabajos. Sin embargo, podemos complicar de inmediato esta tesis al afirmar que Badiou más tarde toma en cuenta un aspecto de la afirmación althusseriana de que no hay sujetos existentes como agentes autónomos junto con la idea aparentemente opuesta de Sartre de que la subjetivación es posible y, de hecho, deseable.

La relación de Badiou con las afirmaciones y vicisitudes del llamado debate humanismo-antihumanismo se desarrolla sobre la cuestión de cómo y por qué retiene y define, no solo una cuestión de quién o qué podría ser el sujeto político colectivo, sino también cuál es el significado que el sujeto podría ser para la filosofía en su totalidad. Su trabajo es un intento de fusionarse e ir más allá del debate, en el que el estructuralismo se opone al humanismo, entrando en un discurso topológico que, no obstante, permite la posible existencia continua de un sujeto, de hecho, podríamos decir que el concepto de sujeto para Badiou es el elemento más consistente de su trabajo.

Mientras Badiou busca alinearse con el antihumanismo de Foucault, Lacan y Althusser, tanto contra el retorno a Kant en el discurso de los derechos humanos como frente a el mal llamado darwinismo contemporáneo que concibe al hombre como un animal finito. Hay indicios, tanto explícitos como implícito, de su pertenencia a una trayectoria más larga, es decir, la crítica de Badiou sobre el sujeto humanista y su propia noción de sujeto, un sujeto que está claramente inspirado en Lacan pero que va más allá de la subjetivación de la falta de este.

Por otro lado, al hablar del campo antihumanista, de Slavoj Žižek, y su crítica lacaniana a Badiou. Se puede ver claramente que es su interpretación diferente de lo Real lacaniano ${ }^{1}$ lo que explica la disputa subyacente entre

1. Este concepto marca el estado de la naturaleza del cual hemos sido separados para siempre por nuestra entrada al lenguaje. Solo como niños neonatos que estuvimos cerca de este estado de naturaleza, un estado en el que no hay nada más que necesidad. La necesidad animal primordial de la cópula (por ejemplo, cuando los animales están en celo) corresponde de manera similar a este estado de la naturaleza. Hay una necesidad 
ambos filósofos. En tanto que el sujeto para Žižek es infundado, por otro lado, la concepción de Badiou de forzar ${ }^{2}$ lo Real confiere al sujeto un grado de consistencia que facilita la articulación de proyectos políticos específicos. Lo que Žižek minimiza de Badiou es el hecho de que no se trata precisamente del sujeto psicoanalítico, ya que seguramente debe seguir siendo en el caso de Žižek en su proyecto de restitución lacaniana, por lo que este último debe preservar la idea de que Badiou permanece en cierto sentido cartesiano, o post-cartesiano de una manera estrictamente endeudada, y por lo tanto en parte lacaniana en la forma en que Žižek lo desea "al concebir al sujeto como el acto (...) después de llenar la brecha ontológica; debemos insistir en el círculo vicioso e irreductible de la subjetividad” (Žižek, 2001, 171).

Si bien, Žižek reconoce una división entre Badiou y Lacan en la cuestión de la identificación del sujeto con la falta, que es imperativo para el psicoanálisis, por otro lado, reconoce una ontologización ilegítima para Badiou, sin embargo, incluye a Badiou con una filosofía de juicio subjetiva, en el modelo de un acto psicoanalítico. En este sentido, el sujeto de Žižek es infundado, por el contrario, la concepción de Badiou de forzar lo Real otorga al sujeto un grado de consistencia que facilita la articulación de proyectos políticos específicos, en particular, su noción de sujeto político, que presta atención y defiende su naturaleza colectiva, procesal y organizada.

\section{El SUJETO EN BADIOU}

Badiou ha reformulado constantemente su noción de sujeto desde su primer trabajo importante, Teoría del Sujeto y en la sección final de, Lógica

seguida de una búsqueda de satisfacción. No obstante, en lo que respecta a los humanos, "lo real es imposible", como le gustaba decir a Lacan. Es imposible en la medida en que no podamos expresarlo en el lenguaje porque la entrada misma al lenguaje marca nuestra separación irrevocable de lo Real. Aun así, lo Real continúa ejerciendo su influencia a lo largo de nuestra vida adulta, ya que es la roca contra la cual fallan todas nuestras fantasías y estructuras lingüísticas. Lo Real, por ejemplo, sigue en erupción cada vez que se nos hace reconocer la materialidad de nuestra existencia, un reconocimiento que generalmente se percibe como traumático, ya que amenaza nuestra propia "realidad", aunque también impulsa el sentido de gozo de Lacan.

2. "Badiou comienza a tejer las primeras indagaciones sobre el sujeto, que lo conducirán a retornar a la idea de Hegel de sujeto como fuerza. Sin embargo, en la segunda mitad de dicha obra, comienza a reproblematizar su mismo concepto de sujeto y desarrolla, influido por la obra de Lacan, lo que llamará la lógica del exceso; punto que lo acercará a las nociones de verdad y acontecimiento” (Exposito, 2015, 219). 
de los Mundos, pero, como él mismo lo reconoce nuca ha abandonado por completo ese tema. Es claro notar como la noción de sujeto siempre ha proporciona el tema unificador de su trabajo. De hecho, su extraordinario libro San Pablo: la fundación del universalismo está dedicado a leer a Pablo no como un apóstol o un santo, sino más bien usando a Pablo como vehículo para redefinir la categoría filosófica de "sujeto" como "universal y singular". El proyecto de Badiou, al leer a Pablo, es nada menos que una refundación de: "una teoría del sujeto que subordina su existencia tanto a la dimensión aleatoria del acontecimiento como a la contingencia pura del ser múltiple, sin sacrificar el motivo de la verdad" (Badiou, 1999, 15).

En otro trabajo interesante La ética: Ensayo sobre la conciencia del mal, Badiou $^{3}$ hizo una crítica mordaz del giro ético en las humanidades y una sólida defensa del legado del antihumanismo de los años sesenta. El giro ético, organiza la existencia práctica en torno a la categoría del bien y dispone cómo nos relacionamos con lo que está sucediendo, en este sentido, el tipo de ética que Badiou critica hace referencia aquella ética fundamentalista y jerarquizada de bienes. La ética se relaciona con el dominio de los derechos humanos y, como tal, presupone la existencia de un sujeto humano universalmente reconocible que es el portador de estos derechos, derechos que de alguna manera están proporcionados naturalmente. Para Badiou, el resurgimiento de esta antigua doctrina de los derechos humanos está estrechamente relacionado con el colapso del marxismo como discurso crítico, como proyecto político y el correspondiente rechazo del proyecto antihistorista y antihumanista de Lacan, Althusser y Foucault. Precisamente, el objetivo de los lacanianosalthusserianos era cuestionar la idea de una identidad natural o espiritual del hombre, sobre la cual se podía fundar cualquier discurso ético y que hoy se rechaza en nombre del ser humano.

En realidad, se suministró la prueba de que la temática de la "muerte del Hombre" es compatible con la rebelión, la insatisfacci6n radical respecto del arden establecido y el compromiso completo en la realidad de las situaciones, mientras que el tema de la ética y los derechos del hombre es compatible con el egoísmo satisfecho de los privilegios occidentales, al servicio de las potencias y la publicidad. Los hechos son esos. (Badiou, 2004a, 31).

3. Badiou le da totalmente otro sentido a la ética. En vez de ligarla a categorías abstractas se la relacionará con situaciones o acontecimientos. 
Para Badiou, entonces, el corazón del problema de la ética contemporánea y con esto quiere decir la ética de la otredad o la ética de la diferencia es la suposición de un sujeto humano universal "es en ese sentido que su anomalía es esa otredad, no como mismidad repetitiva que se cancela en su operación dialéctica para darse paso en una renuncia que se inaugura nuevamente, sino en el allí que se desborda para el acontecimiento de una posibilidad" (Guerra, 2017, 2008). Badiou esboza tres objeciones a esta idea, primero: reduce al ser humano a un estado animal; segundo, supone que el mal precede al bien y que toda aspiración al bien dará como resultado el mal; y tercero, evita que las personas piensen en la singularidad de las situaciones. Tal ética simplemente evade la cuestión de la verdad y se puede decir que: una verdad es algo que tiene lugar en un momento particular y bajo circunstancias particulares. Una ética basada en la noción de verdad, por lo tanto, tendrá que tener en cuenta la singularidad de este suceso.

En contraste con la ética de la otredad, Badiou describe lo que él llama una ética de las verdades basada en tres premisas alternativas: primero, el ser humano debe ser identificado por su pensamiento afirmativo; luego, el ser humano debe ser identificado por su capacidad para el Bien; y finalmente, toda la humanidad tiene sus raíces en la identificación en el pensamiento de situaciones singulares. El problema central para Badiou es no pensar la diferencia -la diferencia es lo que hay-, el desafío es pensar lo mismo. Lo mismo es lo que puede llegar a ser a través de una fidelidad a la verdad. Lo que nos define como sujetos en el sentido de Badiou es nuestra capacidad de verdad, es decir, nuestra posibilidad de ser lo mismo. "En consecuencia, en la matriz de este pensamiento, la verdad ya no es Una, sino que se disemina en cuatro procesos en los que se da la posibilidad de su acontecimiento: la política, la ciencia, el arte y el amor" (Mosquera, 2005, 244). Un procedimiento de verdad rompe con el principio axiomático que gobierna la situación y organiza sus repeticiones según la lógica del mercado, en otras palabras, la proliferación de subjetividades como simplemente tantas identidades equivalentes según las prerrogativas uniformes del mercado. Para Badiou, por otro lado, un procedimiento de verdad no puede basarse en una identidad. "Ya que, si es cierto que toda verdad surge como singularidad, su singularidad es inmediatamente universalizable. La singularidad universalizable provoca una ruptura con la singularidad identitaria" (Badiou, 1999, 30). 
Otro término para esta singularidad universal es "el sujeto", un sujeto cuya fidelidad a la singularidad del acontecimiento ${ }^{4}$ se constituye como un sujeto de verdad. De esto se deduce que el sujeto no preexiste al acontecimiento que expresa, la declaración que es crucial en la medida en que la verdad es un proceso y no un momento de iluminación. Además, la verdad es: “indiferente al estado de la situación” (Badiou, 1999, 34). Por lo tanto, el otro desde la perspectiva de Badiou no puede ser una categoría ética. La diferencia sustancial es simplemente una indiferencia ética, en el sentido de que el ser humano solo se convierte en sujeto a través de un compromiso específico en una decisión veraz.

Ahora bien, se puede decir que, uno de los trabajos de Badiou mayor influenciados por lacan es Teoría del Sujeto, pero incluso aquí insiste en la necesidad de trasponer Lacan para evitar caer en la religión o el cientificismo. No obstante, atravesar a Lacan es ir más allá de él y no rechazar la percepción del sujeto lacaniano per se, por lo tanto, Badiou hace una distinción crucial entre los procesos de subjetivización y el proceso subjetivo. Ambos procesos se pueden encontrar en Lacan. El primero obedece a la lógica del significante y la ley estructural de la falta que se puede encontrar en el trabajo de Lacan hasta mediados de los años sesenta.

Este último se rige por la lógica topológica del nudo borromeo, lo real como exceso y consistencia, y se puede encontrar en su trabajo posterior a 1968. Badiou difiere de Lacan en dos aspectos: primero, argumenta que lo Real otorga al sujeto un grado de consistencia; y segundo, que Lacan no tiene una concepción de la fuerza o frozamiento. El sujeto emerge del cruce de estas dos operaciones o temporalidades; la subjetivización es una interrupción del estado de cosas y se distingue del proceso subjetivo a través de la anticipación de su propia certeza. El proceso subjetivo opera après-coup para conferir consistencia a los efectos de la subjetividad, es decir, "el proceso subjetivo es la fundación retroactiva de la subjetivación en un elemento de certeza que sólo la subjetivación hizo posible" (Badiou, 2009, 272). El sujeto es el producto de esta división dialéctica de destrucción y recomposición, de la ley estructural de la falta de Lacan, el lugar de la falta y el exceso de lo Real que excede este lugar.

En todos los casos, el sujeto procede de una subjetivación en forzamiento de plaza vacía, que un nuevo orden funda retroactivamente como plaza, al

4. "En francés es evénement y se usa para definir tanto acontecimiento como evento en este sentido aquí utilizaremos el termino acontecimiento” (León, 2019,43). 
haberla ocupado. Pueblo multinacional, cardinalidad sucesora, son el proceso que la existencia forzada de lo inexistente anticipa. Todo esplace es así el l'aprés-coup de la destrucción de otro. La subjetivación es la anticipación cuya estructura es la plaza vacía; el proceso subjetivo, la retroacción que emplaza [place] el forzamiento. (Badiou, 2009, 284).

El sujeto es el lugar, que proviene de lo que ha sido destruido, es decir, la aparición de una nueva estructura, en la cual un sujeto no solo ocupa, sino que excede el lugar de la falta en la estructura anterior, hace que la primera se vuelva obsoleta. El sujeto de Badiou es a la vez el lugar de la falta y lo que viene a llenar el lugar. Lo que diferencia a este sujeto del sujeto de Lacan es que lo Real le confiere un grado de consistencia que le permite reconfigurar las consecuencias de su acto inicial de destrucción. Como Badiou lo expresará en, El Ser y El Acontecimiento, la "la teoría del sujeto es unilateral, en la medida que identifica de manera absoluta "sujeto" y sujeto de una verdad" (Badiou, 2004b, 7). Es esto lo que da consistencia al tema y facilita su agencia afirmativa.

En Lógica de los Mundos. Badiou reafirma la dialéctica del esplaces que describió en su trabajo Teoría del Sujeto. ¿Pero qué hay de nuevo en este libro? "una teoría completamente original del cuerpo-sujeto" (Badiou, 2008, 121). La doxa contemporánea es que "No hay más que cuerpos y lenguajes" (Badiou, 2008, 17), una doxa que Badiou denomina materialismo democrático y rechaza porque reduce a la humanidad a una forma de animalidad o bioética. Sin lugar a dudas, el ser humano es una especie animal. "Si bien el individuo, que Badiou llama "animal humano", se contenta con sobrevivir en el mundo tal como es, el Sujeto se posiciona frente al acontecimiento, frente a lo que le sucede al mundo" (Vinolo, 2019, 296). Para Badiou, tenemos un sustrato biológico, físico, pero un animal es un ser mortal; vive, sobrevive y muere. Un cuerpo no es más que el potencial de tener una forma subjetiva y facilita la aparición de verdades en el mundo. Ser humano, o mejor ser un sujeto en el sentido de Badiou es ser inmortal, es rechazar la mera supervivencia $\mathrm{y}$ trascender nuestras situaciones particulares.

5. El esplace del sujeto, es decir, el modo de ser del sujeto, se encuentra en la inconmensurabilidad entre la forma y el contenido; entre la ontología del lugar del ser y el modo del ser iónico actualizado. Badiou argumenta, por lo tanto, que "el esplace como fundamento general de la dialéctica, cuyo horlieu no es sino ficticiamente motor". (Badiou, 2009, 44). "Badiou elabora su teoría del sujeto aplicando esta lógica del entrecruzamiento dialéctico a la tensión entre fuerza y lugar, y a la tensión entre subjetivación y proceso subjetivo" (García, 2013, 17). 
Pensar el concepto de lo humano es pensar lo que está más allá de la fragilidad del cuerpo, de nuestro sustrato animal, o como Badiou lo dice muy bien "bípedo implume cuyo encanto no es evidente" (Badiou, 2004a, 37). El hombre, o el humano, en el sentido de Badiou, no es "otra cosa que un mortal” (Badiou, 2004a, 36), algo más que un ser hacia la muerte. Como Badiou escribe en, Lógica de los Mundos. "A todo animal humano le es acordada, muchas veces (...) su breve existencia” (Badiou, 2008, 136). Es en este sentido lo que podemos entender es que el rechazo de Badiou al énfasis actual en los derechos humanos es demasiado limitante, equivale a poco más que los derechos contra la muerte, los derechos de supervivencia contra la miseria ignominiosa. Los derechos del hombre propiamente dichos deben ser los derechos a la inmortalidad, los derechos afirmativos al infinito contra la contingencia del sufrimiento y la muerte que definen nuestro estado animal.

Contra esta noción occidental de materialismo democrático, Badiou se opone a la dialéctica materialista y a la proposición de que:

No hay más que cuerpos y lenguajes, sino que hay verdades". El "sino que" existe en tanto sujeto. Dicho de otro modo: si un cuerpo se revela capaz de producir efectos que exceden el sistema cuerpos-lenguajes ( $\mathrm{y}$ tales efectos se llaman verdades), se dirá de ese cuerpo que esta subjetivado. (Badiou, 2008, 63).

Las verdades, en el sentido de Badiou, son cuerpos incorpóreos, lenguajes sin significado, que emergen y permanecen suspendidos entre el vacío y el acontecimiento; En la medida en que la verdad no tiene una existencia sustancial, esta exhorta como una excepción a lo que hay. En este sentido el sujeto de verdad es también, en términos zizeaknos, tampoco una sustancia "En la medida en que lo es de una verdad, un sujeto se sustrae a toda comunidad y destruye toda individuación” (Badiou, 2008, 25). Esta idea de sujeto o cuerpo subjetivable es la que se muestra en, Lógica de los Mundos.

De acuerdo a Badiou, hoy existen tres formas dominantes del sujeto: el fenomenológico o el descriptivo; el moral o normativo; y el ideológico o crítico. No obstante, para Badiou, una teoría del sujeto debe ser axiomática, en el sentido de que un sujeto se afirma a sí mismo. De igual manera, si existen verdades, entonces debe haber una forma activa e identificable de su producción. El resultado de esta operación es la realización de tipos específicos de sujeto: el sujeto fiel que mantiene una fidelidad a la verdad y es nada menos que la activación del presente de la verdad; el sujeto reactivo que niega la verdad y Badiou cita a sus viejos adversarios, los nuevos filósofos de la década de los setenta, 
como ejemplos; y el sujeto oscuro que oculta la verdad, y aquí podríamos citar todas las formas de fundamentalismo religioso. Para Badiou, entonces, el sujeto es un hecho bastante raro que surge en relación con un procedimiento de verdad. El sujeto llega a ser a través de su reconocimiento de la singularidad del acontecimiento y su fidelidad a la verdad de este momento.

\section{LA CRÍTICA DE ŽIŽEK AL SUJETO DE BADIOU}

Pasemos ahora a esa otra figura controversial y uno de los más importantes filósofos de la actualidad, Slavoj Žižek. En una nota final de Lógica de los Mundos, Badiou observa que ambos comparten un cierto residuo de la cultura estalinista y forman un buró político de dos, la última facción de los antihumanistas y partidarios del desánimo. Pese a, las diferencias políticas entre los dos, tienen ciertas similitudes sobre todo en sus respectivas teorías del sujeto y su relación con lo Real lacaniano. La crítica de Žižek a la teoría del sujeto de Badiou gira en torno a la distinción entre sujeto y subjetivización que se discutió anteriormente y la función fundamental de la pulsión de muerte en este proceso. Desde la perspectiva de Žižek, el sujeto de Badiou, es decir, el sujeto de la verdad, solo emerge después del acontecimiento a través de un procedimiento de verdad y, por lo tanto, no tiene en cuenta la distinción entre el sujeto, como falta, brecha, vacío, nada, y la subjetivización como un proceso de interpelación.

Precisamente, el sujeto de verdad es, en cierto sentido, secundario al sujeto lacaniano ${ }^{6}$ como falta. Para Lacan, argumenta Žižek, el sujeto es antes de la subjetivización. Es decir, la pura negatividad de la pulsión de muerte, o su inversión en la identificación con algún nuevo significante maestro. El sujeto es simultáneamente la falta ontológica, es decir. "la subjetividad emerge cuando la substancia no puede alcanzar la plena identidad" (Žižek, 2020, 35), en el orden simbólico y lo que viene a llenar el vacío: "La subjetividad es el nombre de esa circularidad irreductible, de un poder que no lucha contra una

6. Lacan al afirmar que el sujeto está dividido, quiere decir también que, como sujeto del lenguaje, siempre mostrará los siguientes dos niveles. El primero es el ego, o sujeto de lo enunciado. Este es el yo en el que el sujeto percibe / anticipa su unidad imaginaria. Dado que el ego es un objeto, según Lacan, es capaz de ser predicado como cualquier otro objeto. Puedo decir de mí más o menos sinceramente que "soy flaco", "honesto" o cualquier otra cosa. De lo que hablará mi oración enunciada en estos casos, para Lacan, es de mi ego. 
fuerza que resiste desde afuera (digamos la inercia del orden sustancial dado), sino contra un obstáculo absolutamente intrínseco, que en última instancia es el propio sujeto" (Žižek, 2001, 172). El esfuerzo del sujeto retroactivamente para llenar la falta se mantiene y genera el vacío en sí. Badiou rechaza esta identificación del sujeto con la falta y, por lo tanto, según Žižek, restringe el acto contingente a un momento de decisión, el momento de subjetivización o el compromiso del sujeto con la verdad de un acontecimiento y, posteriormente, su fidelidad a este momento. A partir de la perspectiva de Žižek, toda la oposición kantiana dentro de Badiou del orden universal del ser y el exceso contingente que sacude a un todo en este orden universal es, por lo tanto, una falsa dicotomía. "La oposición entre el sujeto qua fundamento ontológico del orden del ser y el sujeto qua emergencia particular contingente es, por lo tanto, falsa: el sujeto es el acto/emergencia contingente que sostiene el orden universal del ser" (Žižek, 2001, 174). En otras palabras, el sujeto es una paradoja, un el elemento particular que sostiene el orden universal, de modo que, Badiou es demasiado kantiano y no lo suficientemente hegeliano.

Para Žižek, la incapacidad de Badiou para distinguir entre el sujeto y el momento de la subjetivización procede de su rechazo a la pulsión de muerte freudiana y la negatividad radical que esto se inscribe en el corazón de la subjetividad. Es la repetición de la pulsión de muerte lo que explica el surgimiento del suceso. Žižek rechaza la lectura tradicional del impulso freudiano que lo vincula con la biología humana y la tendencia de un organismo a volver a un estado inorgánico. La paradoja de la pulsión de muerte freudiana es, por lo tanto, la forma en que aparece la inmortalidad dentro del psicoanálisis, por un extraño exceso de vida, por un impulso "no-muerto" que persiste más allá del ciclo de vida y muerte biológica de generación y corrupción.

La última lección del psicoanálisis es que la vida humana nunca es solo vida, es decir, los humanos no están simplemente vivos, están poseídos por el extraño impulso de disfrutar la vida en exceso, apasionadamente unidos a un excedente que sobresale y descarrila el funcionamiento ordinario de las cosas. Para Žižek, entonces, es la pulsión de muerte freudiana que se encuentra en la raíz de la inmortalidad de Badiou, es la pulsión de muerte que nos hace más que animales, que nos hace vivos. La pulsión de muerte no tiene nada que ver con la voluntad de auto-aniquilarse, pero es la razón por la cual esta voluntad nunca se realiza y el sujeto se atasca en objetos parciales. Si la metonimia del deseo es la búsqueda infinita de un objeto perdido, entonces el impulso designa cómo el deseo se fija o atora en un objeto específico, "condenado a circular por él para siempre”. (Žižek, 2006, 38). 
Es el movimiento mudo, repetitivo y rotativo del impulso, afirma Žižek, que es el principal y, en última instancia, el terreno sin fundamento de la libertad humana. La impulsión de muerte está más allá de la mortalidad humana; es un intermediario ensombrecido entre ser y el acontecimiento en los términos de Badiou, o la mortalidad del individuo y la inmortalidad del sujeto. La pulsión de muerte es un nombre para la subjetividad como el vacío de la negatividad radical e irreducible a cualquier forma de inscripción o representación positiva. Es la pulsión de muerte la que facilita la distinción de Žižek entre el sujeto como falta, como pura negatividad, como nada, y lo que él llama subjetivización, en el sentido de Badiou de un sujeto del acontecimiento, como secundario a este momento de pura negatividad. El acto elemental de libertad, entonces, es la negación que está diciendo "No" al gran Otro; se está escapando del circuito repetitivo cerrado de la pulsión de muerte y afirmando una distancia mínima, una brecha de paralaje, entre lo real y lo simbólico.

El radicalismo del impulso freudiano reside en esta negatividad detrás de toda afirmación. La pulsión de muerte es una estructura de auto sabotaje y el requisito previo mínimo para la libertad subjetiva. En este sentido, la pulsión de muerte desplaza al sujeto y abre el espacio mínimo para que un sujeto actúe. Žižek desarrolla esta crítica aún más en su obra maestra, Menos que Nada y señala que deberíamos agregar a la tríada de Ser / Mundo / acontecimiento de Badiou un cuarto término, es decir, la noche del mundo o impulso de muerte:

Badiou distingue al hombre como "animal humano" mortal, del sujeto "inhumano" como agente de un procedimiento-verdad: como un animal investido de inteligencia y capaz de desarrollar instrumentos para alcanzar sus metas, el hombre persigue la felicidad y el placer, se preocupa de la muerte, y así sucesivamente; pero solo como sujeto fiel al Acontecimiento-Verdad el hombre se alza realmente sobre la animalidad. (Žižek, 2015, 689).

Ahora bien, ¿qué ocurre con esta distinción si introducimos la noción freudiana del inconsciente? Lo que distingue a los humanos de los animales incluido el humano-animal no es la conciencia. Podemos aceptar que los animales tienen cierto grado de autoconciencia, pero los animales no tienen un inconsciente. Desde una perspectiva freudo-lacaniana, esto es lo que distingue a los humanos de los animales: 
Habría que decir entonces que el Inconsciente, o más bien el dominio de la "pulsión de muerte", esta distorsión o desestabilización de la vida instintiva animal, es lo que hace a una vida capaz de transformarse en un sujeto de la Verdad: solo un ser viviente con un Inconsciente puede devenir receptáculo de un Acontecimiento-Verdad (Žižek, 2015, 690).

La gran idea de Freud, según Žižek, es que no hay solamente un ser humano, sino que tampoco hay un animal humano. De hecho, Žižek lleva esto un paso más allá al sugerir que, de todos modos, no hay animales, si se trata de un ser vivo totalmente adaptado a su entorno. Desde su nacimiento, el ser humano es arrancado de sus limitaciones animales y sus instintos se desnaturalizan por la circularidad interminable de la pulsión de muerte por lo que Slavoj Žižek y Eric Santner llaman: carácter no-muerto o exceso de vida. El antihumanismo de Žižek parece, al principio, ser aún más radical que el rechazo de Badiou de la concepción materialista democrática de los cuerpos y los idiomas, pero, como se mostrará más adelante al establecer el sujeto con la falta de elementos de la pulsión de muerte, el sujeto de Žižek es incapaz de configurar las consecuencias de sus acciones.

\section{LA RELACIÓN DEL SUJETO CON LO REAL}

En el debate entre Žižek y Badiou sobre la cuestión del sujeto que en definitiva se centró en sus respectivas lecturas de lo Real lacaniano y la relación del sujeto con lo Real. La lección que Žižek extrae de esto es que el sujeto lacaniano es una respuesta a lo Real que emerge en el límite de lo simbólico y, como tal: "Este sujeto se ve totalmente des-sustancializado; coincide con su propio fracaso-en-ser, es un mero corte, una brecha en el orden del ser" (Žižek, 2015, 695). No obstante, la insistencia de Žižek en la primacía de la negación y el sujeto como falta plantea el problema de cómo podemos explicar el grado de consistencia que el sujeto requiere para la acción afirmativa y los proyectos políticos. Žižek, como a menudo se ha señalado a sí mismo, ofrece una crítica extraordinaria de las estructuras fantasmáticas de la sociedad capitalista, es mucho menos claro sobre cómo podríamos enfrentar esas estructuras hoy en día. Es aquí donde el sujeto de verdad de Badiou tiene una ventaja política más fuerte. Es claro que, la formulación temprana de dividir y forzar lo Real en su libro Teoría del sujeto, proporciona al sujeto un grado de consistencia que aborda algunas de las aporías del sujeto lacaniano. 
Slavoj Žižek, en el lapso de su estudio de dos décadas sobre el trabajo de Badiou, ha identificado algunas veces la brecha que separa a Badiou de Lacan y el psicoanálisis. En su primera explicación extendida de la filosofía de Badiou: Psicoanálisis y Posmarxismo: el caso de Alain Badiou. Žižek identificó, el dominio del mito de Lamella ${ }^{7}$ como lo que cristaliza la brecha entre Badiou y Lacan:

Cuánto espacio separa Badiou de Lacan. Para Badiou, lo que el psicoanálisis proporciona es una idea del entrelazamiento mórbido de la Vida y la Muerte, de la Ley y el deseo, una idea de la obscenidad de la Ley como la "verdad" del pensamiento y la postura moral que se limita al Orden del Ser (...) Para Lacan, por otro lado, el Evento de la Verdad opera solo en un contexto de encuentro traumático con la Cosa no muerta / monstruosa (Žižek, 1998b, 247).

En el libro, El Espinoso Sujeto. Žižek insiste en que es la distinción dentro de Lacan entre el sujeto y la subjetivación lo que lo distingue de los postmarxistas, de la misma forma que a Badiou. Más recientemente, en algunos textos como, Menos que Nada, Visión de Paralaje, entre otros Žižek ha argumentado que lo que finalmente diferencia la noción de Badiou de acontecimiento, en contraste con el radicalismo del acto de Lacan, es su negativa a aceptar la primacía de la pura negatividad de la pulsión de muerte. Lo que vincula estas diferencias moderadas entre Badiou y Lacan, el dominio entre dos muertes, el sujeto como falta, la pura negatividad del impulso de muerte, el encuentro con lo Real, es el estado de lo Real mismo. De esta manera se puede decir, que su respectiva conceptualización de lo Real es la esfera nodal de sus múltiples puntos de contención.

\section{5. ŽIŽEK: LA BRECHA DE LO REAL A LO SIMBÓLICO}

Sin lugar a dudas, Žižek ha hecho más que cualquier otro teórico contemporáneo para reorientar nuestra comprensión de Lacan en torno al concepto de lo Real, pero ese Real, como Žižek reconoce y utiliza por completo, es una noción inherentemente paradójica. Es necesario, entonces, comenzar

7. "lo Real que transforma lo imaginario en una experiencia traumática y aterradora (mito de la lamella, de una sustancia que evoca el goce puro del Ser), que se traga en el abismo la identidad; lo Real como una fisura en la red simbólica misma, entendida como la Cosa monstruosa envuelta en el consenso intersubjetivo; y lo Real como el objeto causa del deseo que es inalcanzable, elusivo, que mantiene una distancia infranqueable con el deseo del sujeto" (Bujana, 2018, 174). 
esbozando ampliamente los contornos principales de lo Real dentro del trabajo de Žižek, destacando solo algunos de los principales cambios que ha experimentado el concepto en los últimos veinte años. En sus primeros trabajos, Žižek enfatizó la imposibilidad de lo Real, es decir, lo Real como un núcleo duro impenetrable que resiste la simbolización, e insistió en la necesidad de mantener la brecha que separa lo Real de lo simbólico. Desde este punto de vista "sólo en el sueño nos acercamos al verdadero despertar, es decir, a lo Real de nuestro deseo" (Žižek, 2003, 78). Al mismo tiempo, enfatizó la importancia de lo Real como un límite interno inherente de lo simbólico, un pliegue dentro de lo simbólico, que le impide lograr su identidad consigo mismo:

En esto consiste la paradoja fundamental de la relación entre lo Simbólico y lo Real: la barra que los separa es estrictamente interna de lo Simbólico, puesto que impide que lo Simbólico “se convierta en sí mismo”. El problema del significante no es su imposibilidad para tocar lo Real, sino su imposibilidad para “alcanzarse a sí mismo”. (Žižek, 1998b, 154).

La función de lo Real como límite interno inherente de lo simbólico es crucial para que Žižek facilite su crítica del posicionamiento del sujeto en Ernesto Laclau, la diferencia sexual en la teoría del sujeto de Badiou y Judith Butler. Lo Real como límite interno proporciona a Žižek una especie de posición predeterminada para radicalizar todas las teorías rivales. Lo Real es esencialmente ambiguo, detona en nuestra vida cotidiana en forma de trauma, desestabilizando el equilibrio que mantenemos, pero al mismo tiempo, como límite interno, sirve como soporte para este equilibrio. Lo Real surge como una respuesta a una pregunta o crisis y, como tal, debe parecer contradictorio, mientras que es producido por la crisis misma. La ambigüedad de lo Real lacaniano no es simplemente un núcleo no simbolizado que aparece inesperadamente en el orden simbólico, en forma de retornos y respuestas traumáticas. Lo Real está al mismo tiempo contenido en la forma muy simbólica representándose inmediatamente por esta forma.

En otro texto muy importante, La permanencia en lo Negativo, Žižek aborda esta paradoja a través de la cuestión de la sustancia de lo Real; "lo Real designa un núcleo sustancial que precede y se resiste a la simbolización y, a la vez, designa el sobrante, postulado o "producido» por la simbolización en sí" (Žižek, 1993, 47). La paradoja central de lo Real lacaniano es que este sobrante no es secundario a alguna causa o sustancia primaria, sino que la sustancia es un 
espejismo invocado retroactivamente por el excedente. Ciertamente la función de la ilusión es invocar la impresión de que hay un Real sustancial detrás de ella. Lo Real en este sentido designa una parte que resiste la inversión en la cosa misma, ahora bien, lo Real es esa X que en cuya enumeración cualquier cuadratura del círculo está condenada al fracaso, es la causa ausente de lo simbólico, algo que solo podemos conocer a través de sus efectos y, al mismo tiempo, algo que no existe previamente y que se postula retroactivamente implicando así una especie de bucle temporal a través de la repetición.

A lo largo de los años, la idea de lo Real de Žižek ha cambiado, pero, al igual que Lacan, nunca abandona por completo sus formulaciones anteriores. En su debate con Judith Butler y Ernesto Laclau. Žižek identificó polémicamente lo Real con el capital, en la medida en que lo Real marca el límite absoluto para la re-significación. Además, comenzó a sugerir la posibilidad de tocar lo Real, cuando se suspenden los marcadores simbólicos que nos alejan de él. Para Žižek lo Real no es una especie de esencia o fundamento no histórico, sino que es la historia del sujeto; en consecuencia, es "algo que se realizará en lo Simbólico o, más exactamente, algo que, gracias al progreso simbólico que tiene lugar en el análisis”. (Žižek, 2003, 87). En este sentido, la lucha de clases es real, real en la medida en que no es simbolizable, no existe una posición neutral desde la cual se pueda simbolizar. La lucha de clases es el núcleo no histórico de una situación histórica. Lo Real es el trasfondo o fundamento inamovible que sostiene la lucha misma y que aceptamos silenciosamente como la esfera de la lucha.

En resumen, lo Real es aquello que, cuando estás comprometido en la lucha, se presupone como el dominio mismo de la lucha. Es decir, para Žižek lo Real no es inmutable sino abierto al cambio a través de un acto verdadero. De hecho, la definición de un verdadero acto lacaniano, a diferencia de la pseudoactividad, es si toca o perturba lo real: "lo Real lacaniano en su forma más radical no es una sustancia presimbólica, sino que más bien emerge a través del redoblamiento de lo simbólico, a través del paso de la alienación a la separación” (Žižek, 2015, 409). En la actualidad, Žižek argumenta que lo Real no es un abismo que elude para siempre nuestro alcance o una cosa inaccesible, sino la brecha que presenta nuestro acceso a él. ¿Es este real, el principio de distorsión el que, según Žižek, Badiou no logra comprender su oposición al ser y al acontecimiento? Žižek, insiste que para Badiou, recalca la negatividad explosiva con lo Real en una nueva verdad consistente, mientras que, para Lacan, cada verdad muestra la estructura de una ficción (simbólica), es decir, ninguna verdad puede tocar lo Real. 
El problema con esta formulación, señala Žižek, es que abre a Lacan el paso al relativismo posmoderno y, por lo tanto, invoca la noción de lo Real en las tres órdenes de Lacan: lo Imaginario, lo Simbólico, lo Real, y en de manera estrictamente homóloga, invoca tres modalidades de lo Real dentro de lo simbólico. El despliegue de lo Real de Žižek siempre es sutil y esclarecedor, pero al mismo tiempo uno puede simpatizar aquí con la opinión de Badiou de que esta comedia de síntomas en última instancia descarta la posibilidad de una adhesión a posiciones políticas específicas.

\section{BADIOU: VIOLENTANDO LO REAL}

En una breve nota al pie de página de Lógica de los Mundos, Badiou señala que la concepción de Žižek de lo Real es "tan evanescente, tan brutalmente puntual que es imposible sostener sus consecuencias” (Badiou, 2008, 616). Y añade: "Al final, los efectos de esa suerte de frenesí en surgimiento, en el que lo real gobierna la comedia de nuestros síntomas, son indiscernibles de los del escepticismo" (ibíd. 616). Para Badiou, el estancamiento fundamental del psicoanálisis lacaniano y su debilidad al pensar en la transformación política radica en su concepción de la falta y el fracaso de Lacan de seguir adelante con su visión de lo Real. Como se mencionó anteriormente, el compromiso más sostenido de Badiou con Lacan se encuentra en su primer trabajo, Teoría del Sujeto. Es importante para el argumento que se está desarrollando aquí que en, Lógica de los Mundos, Badiou señala que los avances posteriores en su pensamiento no han invalidado las ideas del libro anterior (cf. Badiou, 2008, 576).

De hecho, Badiou ha conservado una comprensión bastante coherente de lo Real lacaniano como el callejón sin salida de la formalización y, por lo tanto, de la necesidad de forzar lo Real desde este primer trabajo. Es en libro, El Siglo, donde Badiou realmente se centra en lo Real, ya que identifica "la pasión por lo real” como la clave para entender el siglo XX. En este trabajo, Badiou destaca el horror y la barbarie de lo Real, en la medida en que el siglo XX fue un siglo de extrema violencia. Lacan siempre reconoció que lo Real fue en parte una experiencia de horror, pero, crucialmente para Badiou, la fascinación e incluso la exaltación de la violencia en el siglo XX siempre estuvo acompañada de la creencia de que de ese horror surgiría un futuro mejor.

Lo Real también es una categoría central en el libro sobre San Pablo. La fundación del universalismo, ya que un procedimiento de verdad es universalizable solo en la medida en que sea compatible "como su punto real, un 
reconocimiento subjetivo inmediato ele su singularidad" (Badiou, 1999, 23). Si no queremos caer en el relativismo posmoderno, debemos reconocer que la verdad de un acontecimiento deriva de su relación con lo Real, de su capacidad de tocar lo Real, aunque, fugazmente. Según Badiou, Pablo reduce el cristianismo a un solo punto la resurrección, es decir, al "acontecimiento-Cristo" (Badiou, 1999, 50). Este evento, para Pablo, hace que todas las enseñanzas anteriores de la iglesia sean obsoletas, además, depende de un sitio específico en su ser (la crucifixión), pero al mismo tiempo debe ser independiente de este sitio si es para producir efectos de verdad y encontrar un universalismo.

Por lo tanto, tenemos tres problemas en juego, la interrupción de una situación, la fidelidad a la verdad del acontecimiento y una nueva inscripción de esa verdad. En este sentido, el sujeto, de verdad, emerge en la intersección de estos tres conceptos (cf. Badiou, 1999, 25). Los críticos de Badiou, incluidos Žižek y Ernesto Laclau, han señalado que el acontecimiento puro de la resurrección se basa en una muerte previa y, por lo tanto, la afirmación positiva del acontecimiento se basa en una negatividad a priori (Laclau, 2004). Badiou rechaza esta crítica argumentando que existe una separación completa entre la muerte de Cristo y su resurrección. El acontecimiento siempre es excedente a la situación y "se presenta como puro don" (Badiou, 1999, 67). El sujeto es siempre un sujeto dividido, dividido entre la muerte y la vida, entre la carne y el espíritu, o, para decirlo de otra manera, el sujeto de verdad emerge a través de la suspensión del camino de la carne y la afirmación del camino del espíritu. Crucialmente, para Badiou, la muerte "no puede ser constitutiva del acontecimiento-Cristo" (Badiou, 1999, 72). La muerte es fundamental para la construcción del sitio eventual, pero la resurrección es un hecho dado por el acontecimiento. La resurrección no se puede inferir de la muerte.

Ahora bien, con todo esto se explorará más a fondo la concepción de Badiou de lo Real a través de la teoría del sujeto y su noción de forzar o forzamiento ${ }^{8}$. Según Badiou, hay dos nociones de lo Real en Lacan: primero, la comprensión estructural de lo Real como una causa que se desvanece o la falta de ser, y segundo, el Lacan topológico tardío, lo Real del nudo borromeo o el ser de la falta, y es esta segunda formulación la que le da a lo Real un mínimo de consistencia. Badiou está de acuerdo con Žižek en la medida en que lo Real es un concepto fundamentalmente paradójico. Pensar "lo real se reduce

8. "Es bueno notar aquí que Alain Badiou prefiere llamar a la labor analítica un "forzamiento" y no interpretación, como es lo común. Forzamiento porque de lo que se trata, precisamente, es de la verdad, y no del sentido" (Diapola y Lutereu, 2016, 250). 
aquí a pensar la auto-anulación de lo que lo hace posible en general" (Badiou, 2009, 85). Pero esto no llega lo suficientemente lejos, argumenta: "como dice Lacan, lo real es el impase de la formalización (...) debemos aventurarnos desde este punto en que la formalización es el callejón sin salida de lo real" (Badiou, 2009, 47), y continua: "Nos hace falta una teoría del pase [passe] de lo real, como brecha en la formalización. Aquí lo real no es únicamente lo que puede faltar en su plaza, sino lo que supera [ce qui passe en force]" (ibíd. 47). Es decir, debemos pensar lo Real como un exceso, como aquello que excede la ley estructural de la falta.

Para ir más allá de lo que Badiou ve como el callejón sin salida del sujeto vacío ${ }^{9}$ y conferirle un grado de consistencia que nos permita pensar en un cambio radical, así como en la aparición de la novedad más allá de la repetición del pasado, debemos pensar en la falta con destrucción. La destrucción está más allá de la ley de la falta y consiste precisamente en la capacidad de hacer realidad lo no repetible dentro de la repetición, para lograr lo nuevo. Cada sujeto, afirma Badiou: “cruza la falta y la destrucción” (Badiou, 1999, 168). Es decir, lo Real como un exceso, la percepción de Lacan era el papel de lo Real como antagonismo, como aquello que siempre agrieta lo social y significa que nunca puede volverse completo.

Ahora bien, si pensamos lo Real solo de esta manera, entonces quedamos atrapados dentro de la realidad de la estructura misma y no podemos pensar en su potencial transformación, no solo deberíamos pensar lo Real como un trauma imposible, insoportable, sino también como algo que, en raras ocasiones, se convierte en el sitio de una verdad nueva y coherente, es decir, lo Real como novedad.

En su libro, Teoría del sujeto, Badiou desarrolló esta idea a través del concepto de forzamiento: no es suficiente exponer simplemente la falta, la causa ausente, también debemos forzar o distorsionar lo Real para "lo que es una verdad genérica, o sea el despojo, en el devenir de lo Verdadero, de todos los predicados, de todas las instancias del saber" (Badiou, 2008, 601). La limitación de Lacan, desde la perspectiva de Badiou, fue su incapacidad para reconocer la fuerza más que lo Real (cf. Badiou, 1999, 255). Es decir, la fuerza como el exceso de lo Real que interrumpe la repetición y produce novedad.

9. "La diferencia que amenaza con mayor empuje la compatibilidad entre los discursos de Lacan y Badiou reside en la localización del vacío. El vacío es el nombre del ser de Badiou, el vacío del sujeto es donde, según Lacan, la estructura lingüística se coloca” (Marqués, 2007, 330). 
La teoría del sujeto se completa solo cuando "logra pensar la ley estructural de la plaza vacía como apuntalamiento puntual del exceso en la plaza" (Badiou, 1999, 282). En resumen, tenemos dos puntos de vista opuestos sobre el sujeto, el sujeto como una repetición consistente, en la cual lo Real existe, y el sujeto como una consistencia destructiva, en la cual lo Real excede. Si bien esto podría no ser estrictamente lacaniano, tiene la ventaja, como se argumentará ahora en la conclusión, de permitirnos pensar en un cambio radicalmente estructural de manera obligada por el propio Lacan.

\section{CONClusión}

La política para Badiou, y según lo que hemos visto se puede estar de acuerdo con él, requiere coherencia o fidelidad a la verdad de un acontecimiento. Esto a su vez demanda una cierta consistencia del sujeto. Lacan, abrió el camino a esta permanencia a través de su última concepción topológica de lo Real como el nudo; pero no pudo aceptar la idea de la consistencia del sujeto. La vergüenza de Lacan con respecto a la consistencia, argumenta Badiou, "proviene de que él establece el corte (del nudo) como su prueba de verdad” (Badiou, 1999, 266).

Badiou, en este aspecto, insiste en que lo contrario de atar el nudo no es cortarlo sino destruirlo y reconstituir algo más en su lugar. Como se mencionó anteriormente, la idea crucial de Lacan era la función de lo Real como el antagonismo que siempre fisura lo social, haciendo que todas las estructuras simbólicas sean incompletas, pero si nos mantenemos al nivel del antagonismo, entonces también quedamos atrapados dentro de la estructura misma, de un impedimento intratable a la revolución social, cuya ejecución hipotecaria es inadmisible e incluso peligrosa. Esto se compensa con una composición de populismo estratégico, descripción sociológica, ontología discursiva y liberalismo cínico.

Desde el punto de vista de Badiou, solo si podemos conferir al sujeto un grado de consistencia que le permita reconfigurar las consecuencias de su acto inicial de destrucción, podemos evitar tal populismo y liberalismo cínico. Frente a Žižek, argumenta Badiou, es solo, a través del exceso de lo Real que una verdad puede surgir de una situación, ya que "lo Real, aunque no exista, produce efectos" (Žižek, 2003, 214) y es mediante la fidelidad de un sujeto a esa verdad que puede tener lugar una reconfiguración de la situación. Desde la perspectiva del exceso de lo Real, la política emancipadora siempre consiste en hacer posible lo que, desde dentro de la situación, se declara imposible. 


\section{REFERENCIAS BIBLIOGRÁFICAS}

Badiou, A. (1999). Pablo: la fundación del universalismo. Barcelona, Anthropos.

BADIOU, A. (2004a). La ética: Ensayo sobre la conciencia del mal. Barcelona, Herder. Badiou, A. (2004b). El Ser y El Acontecimiento. Buenos Aires, Manantial.

Badiou, A. (2005). El Siglo. Buenos Aires, Manantial.

Badiou, A. (2008). Lógicas de los Mundos: El ser y el acontecimiento, 2. Buenos Aires, Manantial.

Badiou, A. (2009). Teoría del Sujeto. Argentina, Prometeo.

Bujana, H. (2018). Política y psicoanálisis en dos actos. Lacan y Žižek. Tesis Doctoral. Universitat Autónoma de Barcelona.

Diapola, E. y Luterau, L. (2016). “Acontecimiento y verdad: la verdad por-venir como verdad a dar". Desde el Jardín de Frend (Colombia)16, pp. 245-254, doi: 10.15446/dfj.n16.58167.

Exposito, J. (2015). "Lógicas del acontecimiento. Alain Badiou como pensador de la crisis del Marxismo". Eikasia. Revista de Filosofía (España) 62, pp. 217-244.

GARCíA, W. (2013). "El doble entrecruzamiento de opuestos en la teoría dialéctica del sujeto de Alain Badiou" The International Journal of Badiou Studies Volume Two Number One (USA), pp. 14-37. https://badioustudies.files.wordpress. com/2016/11/wenceslao-garcc3ad-puchades-el-doble-entrecruzamiento-deopuestos-en-la-teorc3ada-dialc3a9ctica-del-sujeto-de-alain-badiou-pp-14-37. pdf (última consulta: 29-10-2019).

García, G. y Aguilar, C. (2017) "Psicoanálisis Y Política: La Teoría De La Ideología De Slavoj Žižek". Errancia Politcas. Revista de Psicoanálisis teórica Crítica y Politica (2017). https://www.iztacala.unam.mx/errancia/v16/polieticas_2.html (última consulta: 30-01-2019).

GUERRA, L. (2017). "Alain Badiou, la condición del arte: sustracción, novedad radical, fuerza-forma”. Tesis Doctoral. Universitat Autònoma de Barcelona (España). https://www.tdx.cat/handle/10803/405637?show=full (última consulta: 15-04-2020)

Jameson, F. (2017). Badiou y la tradición francesa. https://newleftreview.es/issues/102/articles/fredric-jameson-badiou-y-la-tradicion-francesa.pdf (última consulta: $28-10-2019)$

LaClau, E. (2004). "Ética del compromiso militante". Virtualia revista de orientación lacanaiana. (Buenos Aires), septiembre-diciembre 2004. Año III. Número 12.

LEÓN, E. A. (2029). "Multiplicidad, acontecimiento y ontología en Badiou y Deleuze" Factótum 21, (España), pp. 42-52.

LeÓn, E. A. (2020). “Deleuze Y Žižek, Una visión De Paralaje”. THÉMATA. Revista De Filosofía (Sevilla), n. ${ }^{\circ}$ 61, pp. 12-22, doi:10.12795/themata.2020.161.01.

Marqués Rodilla, C. (2007), “Sobre el sujeto: ¿Deleuze versus Badiou?”, Éndoxa: Series Filosóficas (Madrid), n. ${ }^{\circ}$ 22, pp. 325-356. 
Mosquera, C. (2015). "Badiou como acontecimiento". Res Publica. Revista de Historia de las Ideas Políticas (España) Vol. 18 Núm. 1, pp. 243-257.

VINOLO, S. (2019). "Subjetivaciones contemporáneas: Alain Badiou y Jean-Luc Marion”. Eidos (Colombia) n. ${ }^{\circ} 31$, pp. 279-306.

ŽızeK, S. (1993). La permanencia en lo negativo.: https://desarmandolacultura.files. wordpress.com/2018/04/zizek-slavoj-la-permanencia-en-lo-negativo.pdf (última consulta: 10-1-2019)

Žızeк, S. (1998a). "Psychoanalysis and Post-Marxism: The Case of Alain Badiou". he South Atlantic Quarterly; Durham; Spring 1998, Vol. 97, 2, pp. 235-261, Copyright Duke University Press.

ŽızeK, S. (1998b). Porque no saben lo que hacen. El goce como un factor político. Buenos Aires, Paidos

Žızeк, S. (2001). El espinoso sujeto. El centro ausente de la ontología política. Buenos Aires, Paidos.

ŽızeK, S. (2003). El sublime objeto de la ideología. Buenos Aires: Siglo XXI Editores Žızeк, S. (2006). Visión de Paralaje. Buenos Aires; Fondo de la Cultura Económica. Žızeк, S. (2015). Menos que Nada: Hegel y la Sombra del Materialismo Dialéctico. Argentina, Akal.

Žıž̇K, S. (2020). El Sexo y el fracaso del absoluto. Barcelona, Paidós. 
